\title{
El Significado Real de que Colombia sea un Estado Social de Derecho
}

\author{
The Actual Meaning of Colombia Being \\ Under the Social Rule of Law
}

\author{
Lizandro Alfonso Cabrera Suárez ${ }^{1} \bowtie$
}

${ }^{1}$ Magíster en Derecho, Universidad Sergio Arboleda, Bogotá. Abogado, Universidad Santiago de Cali. Investigador júnior, Colciencias. Docente de Posgrados, Universidad de la Amazonía y de la Universidad Santo Tomás de Bogotá.

Correo electrónico: Ilzandrocabrera@hotmail.com

Recibido: 25 de octubre del 2017 Aprobado: 20 de diciembre del 2017 Disponible en línea: 1 de abril del 2018

Cómo citar este artículo: Lizandro Alfonso Cabrera-Suárez. El significado real de que Colombia sea un Estado Social de Derecho. DIXI 27. Abril 2018. doi: https://doi.org/10.16925/di.v20i27.2390

\section{Resumen}

Objetivo: el ejercicio consistirá en establecer las significaciones de los conceptos tratados en relación con el principio del Estado Social de Derecho en Colombia.

Metodología: en efecto, ¿qué significa que Colombia sea un Estado Social de Derecho? La expresión significa que los constituyentes en representación del pueblo decidieron una forma específica de Estado con exclusión de otras. Pero ¿qué lo caracteriza?

Resultados: se trata de un tema supremamente rico y lleno de implicaciones que, aunque daría para escribir libros enteros, se presentará de manera sintética intentando reunir todos los elementos importantes de la discusión a su alrededor.

Conclusiones: si no hay Estado de Derecho, no existe democracia. El Estado Social de Derecho se esfuerza también en la realización de los derechos sociales fundamentales.

Palabras clave: Constitución, derecho, Estado, social. 


\title{
The Actual Meaning of Colombia Being Under the Social Rule of Law
}

\begin{abstract}
Aim: The exercise will consist in establishing the meanings of the concepts related to the principle of the Social Rule of Law.

Methods: Indeed, what does it mean that Colombia is under the Social Rule of Law? The expression means that the constituents representing the people decided on a specific form of State and excluded others. But what characterizes it?

Results: While being a supremely rich topic full of implications about which entire books could be written, it will be presented in a summarized manner trying to gather all the important elements of the discussion around it.

Conclusions: If there is no Rule of Law, there is no democracy. The Social Rule of Law also strives for the realization of fundamental social rights.
\end{abstract}

Keywords: Constitution, law, State, social.

\section{O Verdadeiro Significado da Colômbia como Estado Social de Direito}

\section{Resumo}

Objetivo: 0 exercício consistirá em estabelecer os significados dos términos relacionados com o princípio do Estado Social de Direito.

Metodologia: o que significa realmente que a Colômbia é um Estado Social de Direito? A expressão quer dizer que os constituintes que representavam o povo decidiram sobre uma forma específica de Estado e excluíram outras. Mas quais são as características?

Resultados: é um tema extremamente rico e cheio de implicações que, embora poder-se-ia aproveitar para escrever livros inteiros, será apresentado de forma sintética, tentando reunir todos os elementos importantes da discussão em torno dele.

Conclusões: se não houver um Estado de Direito, não há democracia. 0 Estado Social de Direito também se esforça para a realização dos direitos sociais fundamentais.

Palavras-chave: Constituição, direito, Estado, social. 


\section{INTRODUCCIÓN}

El artículo 1 de la Constitución Política establece el tipo de Estado que es Colombia, así: "Colombia es un Estado Social de Derecho, organizado en forma de república unitaria, descentralizada, con autonomía de sus entidades territoriales, democrática, participativa y pluralista, fundada en el respeto de la dignidad humana, en el trabajo y la solidaridad de las personas que la integran y en la prevalencia del interés general".

En filosofía política, se conoce una vieja discusión que se refiere a la concepción del ser humano frente al Estado y a los tipos de relaciones existentes entre ellos, los cuales los acercan o los alejan. Las implicaciones son muchas: en lo social, lo económico, lo moral, etc. A efecto, conocemos la dupla entre liberalismo y socialismo. Al primero lo situamos a la derecha y al segundo, a la izquierda, se dice desde el Abate Sieyés. De corte netamente individualista el uno, de corte netamente colectivista el otro. Al uno le interesa el sujeto libre del Estado; al segundo, el Estado mientras deba existir le ha comprometido en su desarrollo. Cada tipo de Estado tiene sus núcleos de concepciones en los órdenes moral, político, social y económico. Para mediar entre estos dos extremos, se creó una tercería que es precisamente el Estado socialdemócrata, situado en el centro.

No obstante, pueden imaginarse cantidades de gradaciones que, según la decisión de los pueblos, se inclinan hacia la derecha o hacia la izquierda, hacia una definición liberal o hacia una definición de corte socialista. En el centro, o en el intermedio (más amplio) entre estos extremos, se establecen formas concretas de Estado. La calidad de la intervención del Estado y su tamaño se debilitan o se fortalecen. Al liberalismo le interesa el sujeto como individuo económico y en su consolidación la representación del mercado es fundamental.

Para el socialismo, no concebir las relaciones con un matiz meramente individualista le proporciona la posibilidad de caracterizarse como solidarista, como colectivista, y por ello puede pensar las relaciones entre los individuos, ya que compromete su desarrollo de manera equilibrada. Al respecto, también el tipo de derechos que cada posición enarbola se presentan como antagónicos: los individuales del hombre, con una predominancia muy fuerte del derecho a la propiedad privada y una visión de desigualdad entre los seres humanos; a su turno, la izquierda cree y defiende los derechos para todos, sociales, económicos, culturales, de orden colectivo y pensando en la propiedad colectiva, fundamentalmente en cabeza del Estado y con una concepción igualitarista de los seres humanos.

La derecha, el liberalismo (el conservadurismo incluido), no tiene idea de actuación estatal más que para pocas cosas y cree que la sociedad está guiada por el mercado, la mano invisible; mientras que la izquierda, el socialismo, establece la idea de la planeación, aparejada con la intervención del Estado en todos los espacios de la vida social. Se había mencionado que el Estado Social estaba en medio, que estaba representado por las ideas socialdemócratas que son las que le corresponden. En realidad, existe un salto que merecería una explicación importante. Se ha dicho socialdemocracia: es nuevo lo de democracia, no se ha dicho social-liberalismo, ni se ha dicho social-individualismo, ni liberalismo social, ni liberalismo socialista. Estas denominaciones bien podrían caracterizar diversas gradaciones de lo intermedio, de la combinación entre esos extremos de los que se viene hablando. Quizá habrá referencias al surgimiento de la democracia al hablar de la idea de la soberanía popular; en tanto, permítase dejar el tema planteado.

Uno de esos posibles medios, Estados intermedios, es el Estado Social de Derecho, que es un Estado de tipo democrático, caracterizado por el reconocimiento de derechos de índole tanto individualista como colectivista (derechos económicos, sociales, culturales), con una idea de propiedad privada, pero sumada a la existencia de su función social. Y a su vez, con una importante labor interventora del Estado en todos los niveles, fundamentalmente en el orden económico, que no puede serle velado con validez, con una idea de igualitarismo con intervenciones necesarias y no siempre obligatorias. Además, debe caracterizarse este tipo de Estado desde otro punto de vista.

Cuando se dice Estado de Derecho, se puede estar hablando de muchos tipos de Estado. Decir Estado de Derecho es introducir una categoría en la que ha sido introducida otra característica importante del Estado moderno. Se habla de la introducción de la problemática de lo que se ha denominado como el gobierno de las leyes, en contraposición al gobierno de los hombres. Es decir, no gobiernan los individuos, no gobiernan los seres humanos, lo hacen de acuerdo con lo establecido en las normas.

El Estado de Derecho se sujeta a la propia normatividad que emite, en tanto que las autoridades y 
los gobernantes lo hacen supeditados a esas mismas normas. El Estado se sujeta al derecho. Es una concepción eminentemente liberal que permea la concepción sobre otro tipo de Estados que puedan concebirse, situados en ese interreino entre los extremos. Podría pensarse en una monarquía sujeta y respetuosa de las normas que se han establecido, no pensando aún en la idea del pacto. Podría pensarse en un socialismo en el que las autoridades colectivistas sujetan todas sus decisiones al derecho que se ha establecido.

Es que el liberalismo y el socialismo clásicos, aunque representan dos extremos, también comparten o pueden compartir una serie de ideas: por ejemplo, los dos son permeados por la idea de la democracia, los dos han creído en la idea del progreso humano, entre otras. No es el espacio para exponer una completa explicación al respecto y establecer todos los detalles filosóficos e históricos de estos extremos.

Bien, a esa concepción intermedia, que es más o menos equilibrada, le asiste una concepción de sometimiento al derecho. Se denomina social porque es intervencionista, porque no se interesa solo por el individuo, sino también por la colectividad, y sus contenidos y acciones en los distintos campos de la vida social se dirigen desde allí. Habrá un eco de esta caracterización cuando el final del artículo que se analiza diga que prevalece el interés general sobre el particular. El Estado Social hoy es por antonomasia democrático y pluralista, pero podría pensarse lo social de una manera diferente.

Tal cuestión ocurrió con motivo de la expedición de la Constitución de 1886, o con la expedición de la Constitución de Rojas Pinilla en 1957, en la que la idea de la Nación, de la soberanía en la Nación, prevaleció sobre una concepción de la soberanía popular. Ello naturalmente trajo y trae sus consecuencias. Por ello, la Iglesia católica pudo ser tenida como el centro de la nacionalidad, con los partidos políticos tradicionales como ordenadores del destino (mal destino, más bien desatino) de nuestra república. Allí se uniformó la sociedad, se la homogeneizó.

La discusión se filtra a un tipo de antropología filosófica, en la que se pregunta y se responde por la concepción que se tiene acerca del ser humano (de los hombres y las mujeres, de los sujetos individuales) y de la sociedad misma, es decir, de la reunión de aquellos. El tipo de Estado que pensó nuestro constituyente era el Estado benefactor, que es social y democrático, pero que venía cayendo en desgracia ante el empuje del neoliberalismo en el mundo. Hoy, conforme se establece en muchos lugares de la Carta de 1991, se tiene una concepción pluralista, democrática, que hace parte de la caracterización del Estado Social de Derecho, que la entiende allí mismo expresada. Se dijo que esta caracterización habrá de informar toda la preceptiva constitucional. Todo para enfrentar el siguiente objetivo base: analizar y establecer el principio del Estado Social de Derecho en la actualidad.

\section{Estado Social de Derecho}

Así como para una época se confeccionó un concepto claro de lo que debía ser el "Estado de Derecho" como organización humana, también se planteó para una nueva época una posibilidad teórica de un Estado que sin dejar de asirse a las normas, no se fincara en ellas como su único recurso para poder ejercer la organización y el orden ante los asociados; ese nuevo concepto decidió nominarse como Estado Social de Derecho. La razón de ser de esta nueva concepción organizativa de un Estado posiblemente surge de reconsiderar el papel del individuo asociado frente al Estado que lo organiza. Ya no se trataba de la preocupación por encontrar justificación a la razón por la cual un Estado debía ser un ente superior al individuo mediante poder y autoridad para lograr su ordenamiento en la sociedad, sino que se trataba de hacer valer a ese ser humano frente a la majestad del Estado.

En el Estado de Derecho era la norma la que, como un mecanismo, permitía el reconocimiento y la defensa del derecho humano. Pero esta elaboración que el legislador hacía de la norma tomaba al hombre como un "conejillo de pruebas", a quien -con posterioridad de la validez de tales disposiciones- se convertía en víctima de la misma norma. Para sofocar esa postura incómoda y a la postre injusta con el hombre mismo, al concepto de Estado de Derecho se le adicionó un calificativo: el de social. Se trata, entonces, de un Estado al que lo rige la norma, pero que para obtener como resultado la ley parte incuestionablemente de factores humanos como la dignidad, el respeto a la convivencia, la realidad de las necesidades humanas, etc., todo lo cual da un tinte más humano a la norma fría, al artículo ajeno a la circunstancia evidente de lo que el hombre es frente a su existencia en una nación.

Al revisar el contenido que de manera rápida he planteado, daría la impresión inicial de estar frente a un símil del conocido sistema organizativo del Estado planteado en la teoría del "Estado liberal", 
característico de una época en la que por resultados provenientes de una pésima organización social como lo fue la Francia de mediados del siglo xviII, precipitó la Revolución francesa como explosión humana a unas difíciles ataduras que desconocían totalmente el valor del ser humano como individuo y ser racional. Lógico resultado fue la proclamación de unas disposiciones que contrastaran abierta y contundentemente la crítica postura aplastante de la clase poderosa y "noble" contra la clase baja y menos favorecida, siguiendo el conocido texto de los Derechos del Hombre ${ }^{1}$, normas estas que generaron un modelo de Estado que se denominó "Estado liberal" y que se convirtió en el Estado gendarme ${ }^{2}$. Por el contario, el Estado Social de Derecho no consagra una libertad concebida como retaliación a una inhumana comprensión de los individuos asociados, sino que rescata el verdadero valor que tiene el hombre por tratarse de ser: un ser humano. Esta connotación implica reconocer en el individuo su calidad de digno y la consecuente postura de respeto que cada uno se merece y merece a los demás congéneres.

Una mirada al hombre bajo la óptica del Estado Social de Derecho impone no solo hacerlo desde el contexto legal, sino también desde el ámbito natural, esto es, que además de necesidades materiales provenientes del ejercicio de su existencia, el ser humano también las tiene de tipo emocional, cultural, espiritual, ideológico, etc., que no por abstractas tienen

1 Véase Declaración de los Derechos del Hombre y del Ciudadano (1789): "El principio de base de la Declaración fue adoptado antes del 14 de julio de 1789 y dio lugar a la elaboración de numerosos proyectos. Tras largos debates, los diputados votaron el texto final el día 26 de agosto. La Declaración de los derechos del hombre y del ciudadano de 1789, inspirada en la declaración de independencia estadounidense de 1776 y en el espíritu filosófico del siglo xviII, marca el fin del Antiguo Régimen y el principio de una nueva era. La Declaración de los derechos del hombre y del ciudadano es, junto con los decretos del 4 y el 11 de agosto de 1789 sobre la supresión de los derechos feudales, uno de los textos fundamentales votados por la Asamblea Nacional Constituyente formada tras la reunión de los Estados Generales durante la Revolución Francesa".

2 Véase Guía del curso "Formación Ciudadana y Constitucional": "Antes del siglo xx se creía que el Estado no tenía capacidad de autoadministrarse y que sus gastos no serían productivos, a pesar de los ingresos que pudieran generarse, de ahí que el Estado fuera un Estado gendarme que solo percibía ingresos fiscales para cubrir los gastos de las autoridades y su intervención en la economía era exigua, por no decir nula. Como consecuencia de esta concepción los gastos del Estado eran muy pocos". Universidad de Antioquia. Facultad de Derecho. Guía Del curso "Formación CiUdadana Y Constitucional”. Disponible en http://huitoto.udea.edu.co/derecho/constitucion/gasto_publico.html menor valor que las primeras, con lo que puede acuñar el denominado principio de la "seguridad humana", que estaba contemplado por los antiguos a través de los denominados brocardos universales de derecho, es decir, lo que el profesor Valencia sostiene:

A perfilar el concepto de las reglas de derecho contribuyó también en amplia medida la distinción establecida por glosadores y comentaristas de los textos jurídico-romanos canónicos y recogida luego por los tratadistas de la materia de los siglos XVI, XVII y XVIII, diferenciando las auténticas o legales de las doctrinales o brocardos, del mismo modo que se distinguía, entre las compilaciones jurídicas medievales, las auténticas u oficiales, sancionadas como tales por el legislador de las que, carentes de autoridad legal, eran debidas a la iniciativa privada. ${ }^{3}$

Bosquejando de manera genérica, se puede afirmar: la idea de lo "humano" invade el concepto de Estado Social de Derecho, mientras que la noción "hombre" lo hace frente al Estado de Derecho. Tal afirmación está respalda en múltiples argumentos extractados del inteligenciamiento que sobre el tenor filosófico insinúa el concepto "Estado Social de Derecho", lo que implica, por ejemplo, discurrir sobre la dimensión del hombre no como "ser biológico", sino como "ser humano". Ya que mientras en el primer supuesto el individuo como ente natural contempla unas exigencias, esto es, unas necesidades provenientes específicamente en cuanto a su materialidad, la segunda contemplación, es decir, el hombre como ser humano, conlleva una complejidad dada la abstracción multifactorial de los elementos que la integran.

Así, por ejemplo: no solamente debe atenderse al hombre en su necesidad funcional biológica: nacer, crecer, reproducirse y morir, sino que además tales exigencias materiales implícitamente conllevan una trascendencia que se evidencia en la calidad del nacimiento: el derecho debe preocuparse por que toda persona nazca en condiciones dignas. No es posible que el Estado desatienda a personas menos favorecidas para adelantar el ejercicio de tan elemental necesidad como es el nacimiento, y más allá, debe protegerse la gestación como el principio fundamental que anima

3 Véase Hernán Valencia Restrepo. NomOARQUICA, PRINCIPIALÍSTICA JURÍDICA O FILOSOFÍA Y CIENCIA DE LOS PRINCIPIOS Generales Del Derecho. Editorial Temis. (2005). Pág. 163, numeral 86. 
el resultado de un ser que tiene las condiciones para enfrentar una verdadera existencia. Así mismo, debe evidenciarse el crecimiento del ser humano bajo circunstancias que correspondan a su condición de ser racional, proporcionándole los medios para su estructuración física, mental y social; igual debe suceder con la reproducción y la muerte de este ser por excelencia.

Baste este análisis para evidenciar la diferencia objetiva entre el hombre como concepto biológico y el hombre como concepto humano. Es aquí donde el Estado Social de Derecho se diferencia de la teoría del Estado de Derecho, puesto que -como ya lo había expuesto- aquel mira al hombre a través de una norma y le consagra aspectos puntuales frente a su materialidad, en tanto que este aplica y considera el derecho atinente a la materialidad y a la integralidad del ser humano.

En nuestro caso de análisis, la "vivienda digna", no se contenta el Estado en su función de garantizar el derecho a esta, sino que debe velar por que esté a la altura de esa dimensión humana, es decir que el hombre como ser humano que requiere una seguridad de techo y cobijo la obtenga en condiciones razonables que se ajusten a esa categoría racional que compromete al conglomerado: la "dignidad". Mi anterior posición afianza la aseveración del autor Gil Claros: "El ser que cuida de sí mismo, vela por lo humano, por la esencia del ser humano, de lo que él es en su naturaleza ante el mundo, dando razón de lo contemplado"4.

Esta idea es congruente con la afirmación del mismo autor quien, en síntesis, explica que la existencia del ser humano debe verse reflejada en un estilo de vida pulido y elaborado, que esté en consonancia con la estética solo captable por la mente racional. Todo lo anterior para definir que el hombre en su vida en cuanto ser humano debe buscar lo mejor, pues su autoestima así lo exige y nada ni nadie tiene por qué limitar esa tendencia a que cada uno busque lo armónico, lo que le produzca tranquilidad y le colme sus ansiedades.

La Constitución colombiana intenta aproximarse a través de la estipulación normativa superior, adentrándose en la consideración del hombre en la sociedad nacional mirándolo en la dimensión humana, captando este aspecto al hacer una lectura del Título I "De los principios fundamentales". Se

4 Véase Mario Germán Gil Claros. Consideraciones EN TORNO A LA ACTITUD FILOSÓFICA EN EL SUJETO MODERNO. Editorial Universidad Santiago de Cali. (2005). Pág. 34. observa que todos ellos buscan afanosamente, a nivel de principios, evidenciar esa jerarquía que imprime la condición racional al hombre biológico: la vida (artículo 11) ${ }^{5}$, la tranquilidad (artículo 12) ${ }^{6}$, la libertad y la igualdad (artículo 13) familiar y el buen nombre (artículo 15) ${ }^{8}$, la existencia frente al ámbito jurídico (artículo 14) ${ }^{9}$, y se complementa con los denominados derechos económicos, sociales y culturales: la honra, la dignidad y la intimidad de la familia (artículo 42) ${ }^{10}$, la igualdad de hombre y mujer en derechos y oportunidades (artículo 43), la especial protección de los niños (artículo 44) ${ }^{11}$ y el que de manera especial interesa para la ilustración de este ejercicio académico: el derecho a la vivienda digna (artículo 51) $)^{12}$

5 Véase Constitución Política de Colombia [Const.] Julio 7 de 1991 (Colombia). Artículo 11: "El derecho a la vida es inviolable. No habrá pena de muerte".

$6 \quad$ Id. Artículo 12: "Nadie será sometido a desaparición forzada, a torturas ni a tratos o penas crueles, inhumanos o degradantes".

$7 \quad$ Id. Artículo 13: "Todas las personas nacen libres e iguales ante la ley, recibirán la misma protección y trato de las autoridades y gozarán de los mismos derechos, libertades y oportunidades sin ninguna discriminación por razones de sexo, raza, origen nacional o familiar, lengua, religión, opinión política o filosófica. El Estado promoverá las condiciones para que la igualdad sea real y efectiva y adoptará medidas en favor de grupos discriminados o marginados. El Estado protegerá especialmente a aquellas personas que por su condición económica, física o mental, se encuentren en circunstancia de debilidad manifiesta y sancionará los abusos o maltratos que contra ellas se cometan".

$8 \quad$ Id. Artículo 15: "Todas las personas tienen derecho a su intimidad personal y familiar y a su buen nombre, y el Estado debe respetarlos y hacerlos respetar. De igual modo, tienen derecho a conocer, actualizar y rectificar las informaciones que se hayan recogido sobre ellas en bancos de datos y en archivos de entidades públicas y privadas [...]".

$9 \quad$ Id. Artículo 14: "Toda persona tiene derecho al reconocimiento de su personalidad jurídica”.

10 Id. Artículo 42: "La familia es el núcleo fundamental de la sociedad. Se constituye por vínculos naturales o jurídicos, por la decisión libre de un hombre y una mujer de contraer matrimonio o por la voluntad responsable de conformarla [...]".

11 Id. Artículo 43: "La mujer y el hombre tienen iguales derechos y oportunidades. La mujer no podrá ser sometida a ninguna clase de discriminación. Durante el embarazo y después del parto gozará de especial asistencia y protección del Estado, y recibirá de este subsidio alimentario si entonces estuviere desempleada o desamparada. El Estado apoyará de manera especial a la mujer cabeza de familia [...]".

12 Id. Artículo 51: “Todos los colombianos tienen derecho a vivienda digna. El Estado fijará las condiciones necesarias para hacer efectivo este derecho y promoverá planes de vivienda de interés social, sistemas adecuados de financiación a largo plazo y formas asociativas de ejecución de estos programas de vivienda”. 
Estos son tan solo algunos de los presupuestos que nuestra Carta Magna plantea frente a la consideración humana del hombre material, incluso llegando a incursionar en ese ámbito intrincado de la economía, a la que considera una parte importante sobre la que el Estado debe ejercer una especial labor, en la función definitiva de la "redistribución de la riqueza", planteando a través de normas especiales el pago de impuestos como deber y obligación del colombiano como miembro de la comunidad nacional (artículo $95)^{13}$, pues deben existir diferencias entre los asociados ya que hay ausencia de homogeneidad frente a la cancelación de estos. Tal figura del Estado Social de Derecho amerita una revisión comparativa con algunos Estados que han adoptado dicho concepto en su ejercicio institucional. Así, por ejemplo:

En Alemania:

De conformidad con Ipsen, se encuentra estipulado el principio de Estado social, en el artículo 20 I de la Ley Fundamental, en virtud del cual "La República Federal de Alemania es un Estado federal democrático y social"14, al que: "podría en principio corresponder el garantizar una existencia mínima en seguridad social, sin embargo, de ello además, el legitimar esfuerzos hacia la justicia social. La cláusula del Estado social presenta en este sentido al mismo tiempo, una característica estructural del Estado (existente) y una estipulación (a realizar) de finalidad estatal".15

\section{En España:}

La Nación española, deseando establecer la justicia, la libertad y la seguridad y promover el bien de cuantos la integran, en uso de su soberanía, proclama su voluntad de garantizar la convivencia democrática dentro de la Constitución y de las leyes conforme a un orden económico y social justo. Consolidar un Estado de Derecho que asegure el imperio de la ley como expresión de la voluntad popular. Proteger a

13 Id. Artículo 95: "La calidad de colombiano enaltece a todos los miembros de la comunidad nacional. Todos están en el deber de engrandecerla y dignificarla. El ejercicio de los derechos y libertades reconocidos en esta Constitución implica responsabilidades [...] Numeral 9: Contribuir al financiamiento de los gastos e inversiones del Estado dentro de conceptos de justicia y equidad".

14 Véase Ley Fundamental de Alemania. (1994). Artículo 20 I. Disponible en http://constitucion.rediris.es/legis/legextr/ ConstitucionAlemana.html

15 Véase Jörn Ipsen. Staatsrecht I. StAATSORGANiSATIONSRECHT 17. Marzo 2008. Traductor José Hernán Muriel-Ciceri. todos los españoles y pueblos de España en el ejercicio de los derechos humanos, sus culturas y tradiciones, lenguas e instituciones.

\section{"TITULO PRELIMINAR}

\section{Artículo 1}

1. España se constituye en un Estado Social y Democrático de Derecho, que propugna como valores superiores de su ordenamiento jurídico la libertad, la justicia, la igualdad y el pluralismo político.

2. La soberanía nacional reside en el pueblo español, del que emanan los poderes del Estado.

3. La forma política del Estado español es la Monarquía parlamentaria" ${ }^{\prime 16}$

Si bien la Constitución Política no consagra específicamente la figura del "Estado Social de Derecho", sí lo plasma de manera evidente en el título primero: "De los principios individuales", en el cual, palabras más palabras menos, integra lo que líneas atrás denominé: la protección y garantía del hombre en el desarrollo de sus funciones biológico-fisiológicas en condiciones acordes a su dignidad.

\section{Los Derechos Humanos en el Estado Social de Derecho}

Una pregunta que se podría formular sería: ¿el concepto "derechos humanos", considerado dentro de la teoría del Estado Social de Derecho, se modifica en su dimensión cognitiva, comparativamente hablando, frente a la teoría del Estado? La respuesta obtenida del análisis que se haga es de valiosa importancia frente a la temática del derecho a la propiedad y del derecho a la vivienda, dado que es allí donde está la esencia sobre la cual cada organización social ha ido construyendo la estructura intelectual implícita en la normatividad para aplicar de manera válida y coherente el concepto de derecho que se requiere para la convivencia.

Primero, se considera al Estado como una organización suprema frente al hombre y es así como, a pesar de que aquel surge por voluntad de este y para su propio ordenamiento, ingenuamente ese concepto supra queda por encima del ser humano y es a este a quien le corresponde reivindicar su "postura" de individuo valioso, sin la cual no hay Estado. Luego, esa búsqueda de posicionamiento del hombre frente

16 Véase Cinterfor. Cinterfor 50 AÑos. OIT/Cinterfor. (2013). Disponible en http://www.cinterfor.org.uy/public/spanish/region/ ampro/cinterfor/temas/youth/legisl/esp/i/index.htm 
al Estado amerita el surgimiento del Estado de Derecho, en el que el hombre tiene valor, pero al estar subyugado a la fría norma se hace necesario entonces continuar la crítica, el estudio y el análisis que permitan ubicar el punto exacto en que el ser humano y sus derechos se encuentran frente al Estado.

Surge así el Estado Social de Derecho y con él, una relativa tranquilidad que ha ido ganando el hombre frente al Estado. Así, Nikken explica:

La sociedad contemporánea reconoce que todo ser humano, por el hecho de serlo, tiene derechos frente al Estado, los cuales este o tiene el deber de respetar y garantizar o bien está llamado a organizar su acción a fin de satisfacer su plena realización. Estos atributos de toda persona e inherentes a su dignidad, que el Estado está en el deber de proteger son los que hoy se conocen como derechos humanos ${ }^{17}$.

Los derechos humanos han tenido un desarrollo gradual durante la historia, pues a medida que pasa el tiempo la sociedad cambia y los derechos toman matices diferentes, ya que están estrechamente vinculados con la realidad política, económica, social y cultural del momento. Un ejemplo de ello es el surgimiento de los derechos y su clasificación en las diferentes generaciones (de primera, segunda, tercera), que aunque están enmarcadas en épocas distintas, surgen de necesidades históricas complementarias, acordes con la evolución de la convivencia en circunstancias de tiempo, modo y espacio.

La situación anterior permite afirmar que el modo de realización de los derechos humanos depende de la situación social, política y cultural de los grupos humanos que los ejercen, defienden y reivindican. Este aspecto es trascendente en el tema de investigación, pues permite ubicar el desarrollo de las diferentes clases de derechos según su aparición en el tiempo, así como determinar si el surgimiento de estos en los diferentes contextos históricos es determinante al momento de realizar un análisis de cada derecho.

\section{Los Principios y el Estado Social}

El aumento de la complejidad fáctica y jurídica en el Estado contemporáneo ha traído como consecuencia

17 Véase Pedro Nikken. El CONCEPto DE DeRechos humanos. Disponible en http://www.uacj.mx/ICSA/carreras/Educacionen DerechosHumanos/1.2.htm un agotamiento de la capacidad reguladora de los postulados generales y abstractos. En estas circunstancias, la ley pierde su tradicional posición predominante y los principios y las decisiones judiciales, antes considerados como secundarios dentro del sistema normativo, adquieren importancia excepcional.

Esta redistribución se explica ante todo por razones funcionales: el derecho, al no poder prever todas las soluciones posibles a través de los textos legales, necesita de criterios finalistas (principios) y de instrumentos de solución concreta (jueces) para obtener una mejor comunicación con la sociedad. Pero también se explica por razones sustanciales: el nuevo papel de los jueces en el Estado Social de Derecho es la consecuencia directa de la enérgica pretensión de validez y efectividad de los contenidos materiales de la Constitución, claramente señalada en su artículo $228^{18}$.

Pero esta no es la única razón que explica el cambio anotado: el desarrollo de la democracia constitucional puso de presente que el órgano legislativo, depositario tradicional de legitimidad popular, debe estar acompañado del control jurisdiccional, que a través de la historia del derecho constitucional moderno ha demostrado ser el órgano más eficaz en la defensa de los derechos de los ciudadanos y los principios democráticos.

Las dificultades derivadas del crecimiento desbordante del poder ejecutivo en el Estado intervencionista y de la pérdida de liderazgo político del órgano legislativo deben ser compensadas, en la democracia constitucional, con el fortalecimiento del poder judicial, dotado por excelencia de la capacidad de control y de defensa del orden institucional. Solo de esta manera puede lograrse un verdadero equilibrio y colaboración entre los poderes; de lo contrario, predominará el poder ejecutivo.

La dispersión de intereses en la sociedad capitalista actual ha diezmado la importancia del concepto de interés general, repercutiendo así en la legitimidad del órgano legislativo y de la ley misma. Esta deficiencia de la legitimidad tradicional ha sido compensada con el fortalecimiento de la capacidad estatal para crear consenso y para encontrar soluciones producto no solo del imperio de la ley, sino también de la

18 Constitución Política, supra, nota 5, Artículo 228: "Las actuaciones [de la administración de justicia] serán públicas y permanentes con las excepciones que establezca la ley y en ellas prevalecerá el derecho sustancial". 
negociación y de la adecuación a las circunstancias específicas del conflicto.

En estas condiciones, la idea de control judicial aparece como la clave funcional para evitar un desbordamiento de poder y para lograr una adaptación del derecho a la realidad social. Depositario de las ventajas propias del sabio alejado de la sociedad, que piensa en la objetividad de los valores, y dotado de las ventajas de quien tiene el compromiso de tomar cotidianamente en consideración "la realidad viviente de los litigios", el juez está en plena capacidad, como ningún otro órgano de régimen político, de desempeñar ese papel ${ }^{19}$. En síntesis, el control ejercido por jueces y tribunales en el Estado constitucional contemporáneo resulta siendo la fórmula para la mejor relación seguridad jurídica-justicia.

De lo dicho se deriva la idea de que el juez, en el Estado Social de Derecho, también es un portador de la visión institucional del interés general. El juez, al poner en relación la Constitución -sus principios y sus normas- con la ley y con los hechos, hace uso de una discrecionalidad interpretativa que necesariamente delimita el sentido político de los textos constitucionales. En este sentido, la legislación y la decisión judicial son ambas procesos de creación de derecho ${ }^{20}$.

\section{El Estado Social de Derecho y Los Derechos Fundamentales}

La fórmula clásica del Estado liberal en relación con la delimitación de los derechos fundamentales consistía en establecer una lista de derechos pertenecientes a esta categoría. Una de las manifestaciones de la crisis del Estado constitucional en la segunda mitad del siglo xx consiste en afirmar que de nada sirve una buena lista de derechos si no se tiene en cuenta el proceso de aplicación. Según esta crítica, el problema fundamental de tales derechos se encuentra en la definición de las relaciones entre ellos y no en la enunciación de los que son. Es relativamente fácil ponerse de acuerdo en los derechos que son fundamentales - de hecho, en los convenios internacionales existe tal acuerdo-, pero es difícil saber, a priori, cómo se aplican.

19 Véase Alexander Bickel. The Least Dangerous Branch. Bobbs-Merrill. (1962).

20 Véase Mauro Capelletti. Le pouvoir DES JUges. Press Universitaire d’aix-Marseille. (1990). Pág. 35.
El asunto es: en caso de conflicto -y esto es lo más corriente- entre dos o tres derechos, ¿cuál debe tener prioridad? El problema fundamental de los valores no es el de su enunciación, sino el de su aplicación. Para la realidad del derecho, es más importante establecer cuáles son los criterios de interpretación y aplicación de las normas que establecer cuál es la lista de aquellas normas que pertenecen a una determinada categoría.

Si lo esencial de la definición de los derechos fundamentales se juega en el ámbito de la relación entre ellos, esto trae como consecuencia: 1) que la definición a priori de todos los que son no tiene mayor importancia; 2) que esta tarea debe ser llevada a cabo por el juez, puesto que la relación entre los derechos es un dato que viene de los hechos (a través de la tutela); 3) de esta manera, en la relación texto constitucional-hecho social se irá construyendo una nueva interpretación de la carta de derechos adecuada a una realidad propia del subdesarrollo (nuevo constitucionalismo para América Latina).

Existe una nueva estrategia para el logro de la efectividad de los derechos fundamentales. La coherencia y la sabiduría de la interpretación y, sobre todo, la eficacia de los derechos fundamentales en la Constitución de 1991 están asegurados por la Corte Constitucional. Esta nueva relación entre derechos fundamentales y jueces significa un cambio fundamental en relación con la Constitución anterior. Dicho cambio puede ser definido como una nueva estrategia encaminada al logro de la eficacia de los derechos, que consiste en otorgarle de manera prioritaria al juez, y ya no a la administración o al legislador, la responsabilidad de la eficacia de los derechos fundamentales. En el sistema anterior, la eficacia de los derechos fundamentales terminaba reduciéndose a su fuerza simbólica.

\section{Noción de Derechos Humanos}

El desconocimiento y la confusión ${ }^{21}$ de los conceptos, así como la imprecisión en su utilización, pueden ser algunas de las causas próximas de muchos contratiempos e incomprensiones entre los individuos en el interior de las comunidades que conforman, dado que con ello se altera la intersubjetividad

21 Una idea confusa (según la percepción), de acuerdo con la clasificación que hace Aristóteles de las ideas, es aquella cuya comprensión permite identificar la idea pero sin que se pueda comprender su naturaleza, por ejemplo: "aspirina es un analgésico", pero no nos deja conocer su naturaleza. 
lingüística ${ }^{22}$, circunstancia que es de común ocurrencia, pero no por ello es de mayor interés para los protagonistas, pues poca o ninguna trascendencia suelen dar las personas del conglomerado social a tan delicada situación para indagar si debido a estos inconvenientes conceptuales es que se generan o desencadenan los conflictos.

La oscuridad de las ideas, nociones, conceptos, etc., en su condición de medios idóneos para la intercomunicación entre los seres humanos, equivale a la generación de una anarquía en la interrelación de los individuos de una sociedad, puesto que conlleva la imposibilidad o, por lo menos, la mayúscula dificultad de mantener la armonía, la precisión y el entendimiento requerido para la natural convivencia humana, toda vez que esta se encuentra cimentada, primordialmente, en una herramienta tan esencial como es el lenguaje.

Prueba de lo anterior es la abundancia de conceptos análogos definidos de diferentes formas y los distintos nombres otorgados a los "derechos humanos", tales como: derechos del hombre ${ }^{23}$, libertades públi$\operatorname{cas}^{24}$ derechos fundamentales ${ }^{25}$, derechos morales, derechos personalísimos ${ }^{26}$, garantías individuales ${ }^{27}$,

22 Para Habermas, la comunicación lingüística (con sus niveles de intersubjetividad) es el medio que les permite a los individuos garantizar la reciprocidad de la ubicación y noción de sus acciones, reciprocidad necesaria para que la sociedad resuelva los problemas de reproducción material. Así, reformula los postulados de la vieja teoría crítica, añadiendo diferentes categorías en los conceptos de acción, trabajo e interacción. Véase Jürgen Habermas. Dominio TÉCNICO Y COMUNIDAD LINGÜísTICA. Editorial Ariel. (1980).

23 Derechos del hombre: expresión histórica contenida en la Declaración Universal de los Derechos del Hombre y del Ciudadano de la Revolución francesa de 1789, contemplando los derechos de la persona en su condición de individuo frente al poder del Estado.

24 Libertades públicas: expresión acuñada por la doctrina francesa para referirse básicamente a los derechos civiles y políticos que debe tener toda persona.

25 Derechos fundamentales: con esta denominación, se hace hincapié en el carácter primigenio de estos derechos, pues resultan básicos y esenciales para el hombre y su realización plena. También, hace énfasis en la idea de que estos derechos son el fundamento de otros derechos derivados y más particulares.

26 Derechos personalísimos: acepción que comprende los derechos relativos a los atributos físicos y morales de la persona.

27 Derechos o garantías individuales: denominación utilizada bajo el predominio de la ideología individualista, al considerarlos como pertenecientes al hombre individualmente considerado en su connotación de persona física, centro y razón de ser de todas las instituciones políticas y sociales. derechos esenciales ${ }^{28}$ y derechos innatos ${ }^{29}$, entre otros $^{30}$; provocan una enorme vaguedad conceptual respecto a esta expresión, lo que se traduce en la constante dificultad de precisar su alcance y naturaleza.

El desacuerdo conceptual es tal que incluso algunos autore ${ }^{31}$ consideran que este término es inconveniente, pues afirman que es tautológico en sí mismo y desde una perspectiva técnico-jurídica puede que no sea la expresión más adecuada; sin embargo, ellos mismos reconocen que es el vocablo preferible entre todos los existentes, pues es el generalmente aceptado por la doctrina y la legislación, hace parte del lenguaje cotidiano y es reconocido por todos los Estados y todos los pueblos. Por eso, en la Declaración Universal de los Derechos Humanos, párrafo 8 del Preámbulo, aparecen bajo esa denominación como "[...] el ideal común por el que todos los pueblos y naciones deben esforzarse [...]"

La terminología referente a los derechos humanos -al moverse en un ámbito de equivocidad y confusión por la abundancia de expresiones y denominaciones que posee- desencadena obvias dificultades al momento de intentar definirlos. El Curso Sistemático de Derechos Humanos del Instituto de Estudios Políticos para América Latina y África (Iepala), siguiendo al tratadista Antonio E. Pérez Luño, considera que "se pueden señalar tres tipos de definiciones de Derechos Humanos:

1. Tautológicas. No aportan ningún elemento nuevo que permita caracterizar tales derechos. Una definición tautológica muy repetida en la doctrina es la que afirma que "los derechos del hombre son los que le corresponden al hombre por el hecho de ser hombre ${ }^{32 "}$.

2. Formales. No especifican el contenido de los derechos, limitándose a alguna indicación sobre su estatuto deseado o propuesto. Una definición formal

28 Derechos esenciales: se consideran como tales a aquellos derechos permanentes e inherentes al hombre y a su esencia, sin los cuales no podría ser propiamente humano.

29 Derechos innatos: con esta expresión, se quiere denotar que esos derechos nacen con el hombre y son valiosos por sí mismos.

30 Véase Red de Promotores de Derechos Humanos. ¿Qué son Los derechos humanos? Defensoría del Pueblo. (2001).

31 Véase Instituto de Estudios Políticos para América Latina y África (iepala). Curso Sistemático de Derechos Humanos. Disponible en www. iepala.es/curso_ddhh/ddhh33.htm

32 Véase Grupo de Investigación Informática Lógica y Derecho de la Universidad de Sevilla. Definición DE LOS DEREChOS HUMANOS SEGÚn PÉrEZ LuÑo. Disponible en http://plesiologos.blogspot. com/2008/02/definicin-de-los-derechos-humanos-segn.html 
es la que afirma que "los derechos del hombre son aquellos que pertenecen o deben pertenecer a todos los hombres, y de los que ningún hombre puede ser privado 33 ".

3. Teleológicas. En ellas se apela a ciertos valores últimos, susceptibles de diversas interpretaciones. Una definición teleológica es la que dice que "los derechos del hombre son aquellos que son imprescindibles para el perfeccionamiento de la persona humana, para el progreso social o para el desarrollo de la civilización ${ }^{34}$ ". A ellas podríamos añadir un tipo más de definición:

a. La explicativa o definición descriptiva. Una definición que pretende ser descriptiva, aunque tiene una fuerte carga teleológica, y que ha sido generalmente aceptada por la doctrina, es la que propone Pérez Luño, quien entiende que los Derechos Humanos son "un conjunto de facultades e instituciones que, en cada momento histórico, concretan las exigencias de la dignidad, la libertad y la igualdad humanas, las cuales deben ser reconocidas positivamente por los ordenamientos jurídicos a nivel nacional e internacional. ${ }^{35}$

Las definiciones en torno al concepto de derechos humanos hacen parte de los múltiples esfuerzos realizados por diversos autores para encontrar una idea clara y precisa de lo que son, pues aunque se coincide en la trascendencia de su consagración, no sucede lo mismo con su definición.

El profesor mexicano José Antonio García Becerra considera que estos intentos de conceptualización se pueden dividir en dos grandes grupos o tendencias: una positivista y otra iusnaturalista dependiendo de la consideración de estos como derechos derivados de la consagración normativa contenida en el orden jurídico o como anteriores o superiores a este ${ }^{36}$.

La definición propuesta antes por Pérez Luño es considerada bajo una tendencia iuspositivista, pues para esta postura los derechos surgen con su consagración en la norma jurídica del derecho positivo.

33 Id.

34 Id.

35 Véase Antonio E. Pérez Luño. Delimitación conceptual de los Derechos Humanos en la obra colectiva. Antonio E. Pérez Luño. Coordinador. LOS DEREChos humanos. SignificaCión, ESTATUto JURÍdico y SISTEMA. Ediciones de la Universidad de Sevilla. (1979). Págs. 14-15.

36 Véase José Antonio García Becerra. TeOría de los DERECHOS Humanos. Universidad Autónoma de Sinaloa. (1991).
Por otro lado, a la tendencia iusnaturalista se circunscriben autores como Harold H. Lasky, quien afirma:

Los derechos son en realidad las condiciones de vida social sin las cuales no puede ningún hombre perfeccionar y afirmar su propia personalidad. Puesto que el Estado existe para hacer posible esta tarea, solo manteniendo esos derechos puede mantener su fin. Los derechos por consiguiente son anteriores a la existencia del Estado, en el sentido de que, reconocidos o no, son la fuente de donde deriva su validez legal.

O como José Castán Tobeñas, quien define los derechos humanos como:

[...] aquellos derechos fundamentales de la persona humana -considerado tanto en su aspecto individual como comunitario- que corresponden a esta por razón de su propia naturaleza (de esencia, al mismo tiempo, corpórea, espiritual y social) y que nos deben ser reconocidos y respetados por todo poder y autoridad y toda norma jurídica positiva, cediendo, no obstante, en su ejercicio a las exigencias del bien común. $^{37}$

La proliferación de nociones que dicen definir los derechos humanos hace necesario tener una definición que permita compendiar sus elementos estructurales, pues solo si se llega a un acuerdo básico sobre su contenido resultará posible establecer su efectividad y garantía. Bajo estas circunstancias resulta pretencioso proponer una definición exhaustiva, pero es fundamental tener una en la que se apoye el resto de la investigación y que proporcione bases acerca de lo que son los derechos humanos, puesto que tratar el tema requiere establecer con certeza cuál es la posición de la "vivienda" y su "adquisición" dentro del tema de los "derechos humanos".

Por lo tanto, se propone tomando como criterio orientador la definición presentada por la Defensoría del Pueblo de Colombia en la obra ¿Qué son los derechos humanos? ${ }^{38}$, la presentada por el doctor Pérez Luño $^{39}$ y la expuesta en el Curso Sistemático de Derechos Humanos ${ }^{40}$, que es la siguiente:

37 Véase Nicolás García Aguilar. La cuestión de la responsabilidad en el Derecho Informático. Revista ElectrónicA De Derecho INFORMÁTICO 2. Septiembre 1998.

38 Red de Promotores de Derechos Humanos, supra, nota 30.

39 Pérez Luño, supra, nota 35.

40 IEPALA, supra, nota 31. 
Los derechos humanos son exigencias de libertades, facultades o prestaciones, directamente sustentadas en la dignidad humana, que revelan lo que en cada momento histórico es necesario para una convivencia justa y pacífica, son congruentes con los valores sociales fundamentales ampliamente compartidos por la comunidad internacional y por esto mismo consideradas merecedoras de protección jurídica en la esfera interna y en el plano internacional.

La definición anterior intenta tomar los derechos humanos como concepto histórico, pues al provenir del hombre, poseen una ubicación real en el mundo y en el desarrollo de la sociedad, no surgen simplemente de premisas metafísicas abstractas, sin una concreta especificación histórica, sino de situaciones y necesidades que se manifiestan con el crecimiento del ser humano ${ }^{41}$.

También, se busca tener como eje central de cualquier definición el valor supremo de la dignidad, el cual constituye el soporte moral de todos los derechos, pues de él se desprende un conjunto de restricciones y normas en el comportamiento hacia las personas, que incluyen la abstención de cualquier trato cruel o degradante, la prohibición de reducir a un ser humano al rango de simple instrumento al servicio de fines ajenos y su reconocimiento como un sujeto de necesidades que merecen ser atendidas. Y por último, pretende establecer una definición formal que pueda ser referida a cualquier momento histórico y pueda responder coherentemente a los planteamientos metodológicos sustentados a lo largo de la investigación.

\section{CONCLUSIONES}

1. Si no hay Estado de Derecho, no existe democracia dado que ese Estado de Derecho excede un simple conjunto de normas constitucionales y legales, pues involucra a todos los ciudadanos no solo a parlamentarios que legislan o a políticos que gobiernan. La existencia del Estado de Derecho se mide en el funcionamiento de las instituciones y en la praxis política cotidiana. El Estado de Derecho suministra la libertad para el libre juego de pensamiento y acciones, y debe permitir las modificaciones que el proceso social requiera. El Estado de

$41 \quad I d$.
Derecho excede el campo de lo jurídico para tocar el terreno de la moral, pues existen derechos naturales inalienables. Así entendido, podemos hablar de un Estado Social de Derecho, pues comprende los derechos sociales de los cuales la población ciudadana es titular.

2. El carácter social del Estado Social de Derecho lo hace -hoy en día- el único justificable moral y políticamente, pues en contraste con el Estado de Derecho -que caracteriza a la sociedad liberal burguesa y que defiende con exclusividad los derechos civiles y políticos-, el Estado Social de Derecho se esfuerza también en la realización de los derechos sociales fundamentales, entre ellos la alimentación, la vivienda, la educación, la salud, el trabajo y la seguridad social.

3. El cambio más significativo del tránsito del Estado de Derecho al Estado Social de Derecho lo constituye la sustitución de una concepción formal de la igualdad por una material, en la cual esta ya no queda librada ante las fuerzas del mercado, sino que depende de la continua y deliberada intervención de las autoridades públicas para promover personas, grupos y sectores desfavorecidos. No es razonable hacer una distribución nominalmente igualitaria cuando los destinatarios de tal distribución están en condiciones desiguales.

4. El Estado Social de Derecho, promulgado por la Constitución de 1991, redefine las relaciones entre el poder central y las regiones, y se convierte en un Estado participativo donde prevalece lo regional sobre lo nacional, se reconoce la diversidad étnica y cultural de la nación, y hay un presupuesto de inversión social. Al igual que en los demás países de la región, las reformas estructurales han traído consigo nuevas formas de relación entre la comunidad y el Estado; este proceso de reformas ha incidido a nivel local y en algunos casos ha servido para que la participación de la sociedad civil sea más tangible.

5. La participación comunitaria a nivel de los municipios ha ido creciendo; a nivel local se expresan demandas concretas que tienen que ver con la cotidianidad de la gente, esto hace muy dinámicos los procesos de descentralización.

6. Es obvia, entonces, la relación entre derecho y política. El derecho emana de la voluntad de los ciudadanos y del Gobierno; es expresión de esa voluntad ciudadana y está limitado en su acción por los derechos que esa voluntad encarna. El logro del bien común es el objetivo genérico del derecho. El 
Estado de Derecho de origen liberal procuraba solo la protección de los llamados "derechos negativos" (protección a la persona y a la propiedad) y negaba los "derechos positivos" (promoción de la persona, rompimiento de la pobreza, ataque a la desigualdad económica). Si bien la democracia es una forma jurídica específica, no puede limitarse a garantizar la alternabilidad en el poder de las diversas expresiones políticas, sino que debe avanzar en la institucionalización de principios y valores de justicia social distributiva. El derecho, para decirlo claramente, es un fenómeno politizado, pues dependerá del consenso alcanzado en democracia. En otras palabras, los derechos sociales deben ser incorporados a los fundamentos del orden estatal mismo. Esto es lo que se llama Estado Social de Derecho y es lo que una democracia del siglo xxI debe profundizar, permitiendo que se plasmen en las conductas políticas democráticas de todos los días la mutabilidad y los desafíos relativos al bien común. Para ello, debe crear canales en los que fluyan las voluntades y se encaucen los procesos de desarrollo de las personas que constituyen todo el entramado democrático. Se requiere, pues, de una cultura política de la legalidad vista como la convicción de que no basta la existencia de un Estado de Derecho para que pueda hablarse de una sociedad justa, pero la sociedad justa solo es perseguible en un Estado de Derecho. Al igual que debemos admitir que es en democracia que se puede proceder a distribuir la riqueza social.

\section{RECOMENDACIONES}

1. La democracia está hecha de los materiales sociales que componen la sociedad democrática. Las normas jurídicas no son legítimas solo por su origen; fundamentalmente lo deben ser por sus efectos. El asunto es el papel del derecho (rule of law) en la fundación y regulación de la democracia. La Constitución es el consenso sobre una concepción de la vida colectiva. En muchas partes, no existe un compromiso -ni de las poblaciones, ni de las autoridades- hacia las reglas del juego democrático encarnado en el derecho. El Estado de Derecho implica principios morales, jurídicos y políticos que deben tener eco en las decisiones judiciales que fomenten el respeto a las reglas fundamentales del juego político. Cuando no se puede intervenir para modificar los esquemas de iniquidad, no estamos ante un real Estado de Derecho. Lo que hemos tenido no han sido democracias representativas, sino democracias delegativas. Es indispensable entonces cerrar la brecha entre el orden jurídico formal y las formas y prácticas de la realidad. Hay que revalorizar el papel del derecho y de la legalidad haciendo reales los derechos fundamentales. Esto que podríamos llamar reinstalación del Estado de Derecho pasa por la modificación de la cultura política que necesariamente debe traducirse en mejores leyes e instituciones. Hemos tenido la mala costumbre de rellenar las Constituciones de enunciados imposibles ampliando así la brecha entre realidad social y texto jurídico, sin que hayamos hecho el esfuerzo de hacer subir desde el cuerpo social las nuevas formas, y permitiendo el alzamiento de un autoritarismo constitucional. No olvidemos que los jueces deben ser la línea entre gobierno y ciudadanos.

2. Hay que plantearse las formas de desarrollo de un discurso práctico en la acción política que cree condiciones sociales aptas mediante la institucionalización del discurso ético, asumiendo el derecho los desafíos planteados a la política en el ámbito cultural y sociopolítico. Este es el nexo estrecho, dado que la complejidad social ha sometido a presión a los regímenes democráticos. Hay una "pluralización de las formas de vida y una individualización de las biografías" que imponen una multiplicación de tareas y roles sociales, por lo cual hay que liberarse de vinculaciones institucionales demasiado estrechas. Así, surge el planteamiento de una democracia deliberativa. El ciudadano deja de ser un sujeto que simplemente expresa preferencias (por ejemplo, electorales) para pasar a ser considerado un agente activo en la construcción del proceso político mediante la modificación del agotado concepto de opinión pública, que pasa a ser una deliberativa.

3. Una cosa es el Estado de Bienestar (seguridad social, tributación progresiva, políticas fiscales y monetarias, etc.) y otra cosa el Estado Social de Derecho. El primero implica conceptos de política económica y social, pero el segundo implica una forma sucesora del Estado Liberal de Derecho, lo que de ninguna manera conlleva una contradicción sin salida. El primero es un conjunto de políticas para imponer correctivos a las injusticias generadas en el sistema capitalista. El segundo implica la imposición de una dirección al proceso 
histórico, esto es, el avance en la búsqueda de la equidad social, la protección de los débiles económicos y, por supuesto, la generación de riqueza por medio del desarrollo integral, pues para que haya que repartir hay que producir.

4. El propósito fundamental del Estado es perfeccionar la democracia, entendida también en sus aspectos jurídico y económico. Esto implica, a mi entender, una reformulación general de principios y una nueva concepción de los derechos fundamentales. Así, he insistido en que la teoría aceptada de que la soberanía radica en el pueblo debe ser cambiada por otra que implique su residencia en el hombre que la ejerce a través del pueblo. Esto evitaría la más feroz de las dictaduras, la ejercida por la mayoría, y pondría los derechos humanos en el primer plano de la teoría y de la acción. El Estado Social de Derecho, al incentivar la organización social, crea nuevos intermediarios entre el poder y la sociedad. Esa organización constituye poder político que se incorpora, de facto, al grupo de división constitucional de poderes. Ello implica la consagración legal de la descentralización, pues facilita la inclusión y el control, la sujeción del mercado al bien común y la inclusión de lo privado en el atributo del Estado sobre lo público, de manera que este ámbito se convierta en un terreno de interacción de propuestas y decisiones en las que el Estado pierde el monopolio. Desarrollar en todos los ámbitos y a plenitud el Estado Social de Derecho es una de las preocupaciones fundamentales que deberá tener una democracia del siglo XXI.

\section{REFERENCIAS}

Alexander Bickel. The Least Dangerous BRANCH. Bobbs-Merrill. (1962).

Antonio E. Pérez Luño. Delimitación conceptual de los Derechos Humanos en la obra colectiva. Antonio E. Pérez Luño. Coordinador. LOS DERECHOS HUMANOS. SigNIFiCACIÓN, ESTATUTO JURÍDICO Y SISTEMA. Ediciones de la Universidad de Sevilla. (1979).

Carl Schmitt. Teoría de la Constitución. Alianza Universidad Textos. (1992).

Cinterfor. Cinterfor 50 AÑos. OIt/Cinterfor. (2013). Disponible en http://www.cinterfor.org.uy/public/ spanish/region/ampro/cinterfor/temas/youth/legisl/ esp/i/index.htm
Ciro Angarita Barón. Soberanía del pueblo y Poder Constituyente. Corporación Viva la Ciudadanía. (1994).

Constitución Política de Colombia [Const]. Julio 7 de 1991 (Colombia).

Daniel Herrera Restrepo. La democracia, una verdad y un valor ético en construcción. Mario Jursich Durán. Editor. SOBERANía POPUlAR Y DEMOCRACIA EN COLOMBIA. Corporación Viva la Ciudadanía. (1992).

Declaración de los Derechos del Hombre y del Ciudadano. (1789). Disponible en https://democraciaparticipativa.net/documentos-data-a-referenda/documentos-en-espanol/documentos-sobre-derechos-humanos/ 10371-declaracion-de-los-derechos-del-hombre-ydel-ciudadano-1789.html.

Grupo de Investigación Informática Lógica y Derecho de la Universidad de Sevilla. Definición DE LOS DEREChos humanos Según Pérez LuÑo. Disponible en http://plesiologos.blogspot.com/2008/02/definicin-de-los-derechos-humanos-segn.html

Hernán Valencia Restrepo. NomoARQUICA, PRINCIPIALÍsTICA JURÍDICA O FILOSOFÍA Y CIENCIA DE LOS PRINCIPIOS GENERALES DEL DERECHO. Editorial Temis. (2005).

Instituto de Estudios Políticos para América Latina y África (iepala). Curso Sistemático de Derechos HumaNos. Disponible en www. iepala.es/curso_ddhh/ ddhh33.htm

Javier Henao Hidrón. PAnorama Del Derecho constituCional Colombiano. Editorial Temis. (1980).

Jörn Ipsen. Staatsrecht I. StaAtsorganisationsRecht 17. Marzo 2008. Traductor José Hernán Muriel-Ciceri.

José Antonio García Becerra. Teoría DE LOS DEREChos HUMANos. Universidad Autónoma de Sinaloa. (1991).

Jürgen Habermas. Dominio TÉCNICO Y COMUNIDAD LINGÜÍsTICA. Editorial Ariel. (1980).

Mario Germán Gil Claros. Consideraciones EN TORNO A LA ACTITUD FILOSÓFICA EN EL SUJETO MODERNO. Editorial Universidad Santiago de Cali. (2005).

Martin Kriele. Introducción A LA TEORÍA DEL Estado. Ediciones de Palma. (1980).

Mauro Capelletti. Le Pouvoir Des Juges. Press Universitaire d'aix-Marseille. (1990).

Nicolás García Aguilar. La cuestión de la responsabilidad en el Derecho Informático. Revista EleCtrónICA DE Derecho Informático 2. Septiembre 1998. 
Ley Fundamental de Alemania. (1994). Artículo 20 I. Disponible en http://constitucion.rediris.es/legis/legextr/ ConstitucionAlemana.html

Luis Carlos Sachica. Nuevo constitucionalismo colomBIANO. Editorial Temis. (1992).

Pedro Nikken. El concepto de derechos humanos. Disponible en http://www.uacj.mx/ICSA/carreras/EducacionenDerechosHumanos/1.2.htm
Red de Promotores de Derechos Humanos. ¿Qué son los Derechos humanos? Defensoría del Pueblo. (2001).

Universidad de Antioquia. Facultad de Derecho. Guía DEL curso "Formación Ciudadana y ConstitucioNAL". Disponible en http://huitoto.udea.edu.co/derecho/constitucion/gasto_publico.html

Vladimiro Naranjo Mesa. Teoría Constitucional e INSTITUCIONES POLÍ́TICAS. Editorial Temis. (1995). 